\title{
Benoît-Marie Solaberrieta, Aimé-Georges Martimort. Un promoteur du Mouvement liturgique (1943-1962)
}

Paris, Éditions du Cerf, coll. « Cerf histoire », 2011, 351 p.

\section{Gaspard Salatko}

\section{(2) OpenEdition \\ Journals}

\section{Édition électronique}

URL : http://journals.openedition.org/assr/26569

DOI : $10.4000 /$ assr.26569

ISSN : $1777-5825$

\section{Éditeur}

Éditions de l'EHESS

\section{Édition imprimée}

Date de publication : 31 décembre 2014

Pagination : 293

ISBN : 978-2-7132-2467-6

ISSN : 0335-5985

\section{Référence électronique}

Gaspard Salatko, «Benoît-Marie Solaberrieta, Aimé-Georges Martimort. Un promoteur du Mouvement liturgique (1943-1962) », Archives de sciences sociales des religions [En ligne], 168 | 2014, mis en ligne le 21 mai 2015, consulté le 22 septembre 2020. URL : http://journals.openedition.org/assr/26569; DOI : https://doi.org/10.4000/assr.26569 


\section{Benoît-Marie Solaberrieta, Aimé- Georges Martimort. Un promoteur du Mouvement liturgique (1943-1962)}

Paris, Éditions du Cerf, coll. «Cerf histoire », 2011, 351 p.

Gaspard Salatko

\section{RÉFÉRENCE}

Benoît-Marie Solaberrieta, Aimé-Georges Martimort. Un promoteur du Mouvement liturgique (1943-1962), Paris, Éditions du Cerf, coll. «Cerf histoire », 2011, 351 p. 
Benoît-Marie Solaberrieta propose une biographie intellectuelle d'Aimé-Georges Martimort, ecclésiastique, dont le nom est attaché à la préparation du Concile Vatican II. Sans céder à la tentation hagiographique, cette contribution à l'historiographie du catholicisme suit plus sûrement l'hypothèse selon laquelle les contributions de Martimort au projet et à l'organisation du concile demandent à être examinées au regard de la formation qu'il a reçue et de l'enseignement qu'il a dispensé dans le cadre de l'Institut Catholique de Toulouse.

Conçu sur l'interprétation des archives et sur la restitution des témoignages recueillis auprès de Martimort lui-même, l'ouvrage se distingue par un souci constant de resituer ces sources dans le contexte d'émergence et d'inflation des recherches liturgiques conduites dans le sillage de la publication, de 1840 à 1851, des Institutions liturgiques, rédigées par Prosper Guéranger, abbé de Solesmes et restaurateur de l'ordre bénédictin. Ce parti de méthode contribue à éclairer certains aspects encore peu documentés de l'historiographie du catholicisme, telle la fondation du Centre de Pastorale Liturgique, le 20 mai 1943, dans les locaux des éditions dominicaines du Cerf, sises au 29, boulevard de la Tour Maubourg, à Paris. Organisée par le dominicain Pie Duployé qui, dès 1939 avait découvert la pensée du Mouvement liturgique par l'intermédiaire de la revue Jahrbuch fur Liturgiewissenschaft, éditée par l'abbaye bénédictine de Maria Laach, cette réunion est marquée par la présence du bénédictin Lambert Beauduin qui y prononce un discours inaugural suite auquel Martimort, alors jeune enseignant, prend spontanément la parole pour rappeler que « la liturgie n'est pas une reproduction archéologique que l'on considère en esthète, ni un instrument qu'on utilise à sa convenance sous prétexte d'adaptation. Par liturgie, il faut entendre non seulement une chose du passé, mais ce qui fait revivre de manière réelle et actuelle la vie du Christ, par l'intermédiaire de signes et de symboles » (p. 70). Remarqué pour sa position réformatrice, étayée par sa connaissance des travaux menés par Louis Duschesne (Origines du culte chrétien, 1880), Pierre Battifol (Histoire du bréviaire romain, 1895) et Anton Baumstark (Liturgie comparée, 1939) concernant l'histoire de la liturgie, Martimort est nommé co-directeur du Centre de pastorale liturgique en 1946. Par l'organisation de conférences annuelles de formation et de recherche réunissant théologiens, universitaires, clercs et laïcs, ce "promoteur du Mouvement liturgique » instille dès lors parmi les différentes mouvances catholiques une pédagogie de la réforme qui, pour être comprise, doit être considérée à l'aune du truchement des expérimentations liturgiques alors émergentes. C'est ainsi que dans une note critique, publiée en 1945 dans la revue la Maison-Dieu (Martimort A.-G., 1945, «Fêtes populaires et missionnaires ", La Maison-Dieu, $\mathrm{n}^{\circ}$ 3, p. 164-170), Martimort fait état de son 
scepticisme concernant les innovations introduites par Georges Michonneau, alors curé de la paroisse de Petit-Colombes, dans le domaine des "paraliturgies » qui, d'un point de vue pratique, consistent en des cérémonies « composées de chœurs parlés, de jeux scéniques, de chants, d'acclamations et de processions » (p. 120) dont B.-M. Solaberrieta associe l'invention à un souci pastoral d'éducation chrétienne et d'initiation à la prière collective dans un contexte de requalification des formats rituels établis.

De fait, l'aspect le plus représentatif de la contribution de Martimort au projet du Centre de pastorale liturgique tient sans doute à l'introduction de la question dite de "l'assemblée ", notion centrale de la théologie catholique contemporaine dont ce théologien fut l'un des principaux artisans. Par la richesse des données relatives à la biographie et à l'œuvre de Martimort, l'ouvrage de B.-M. Solaberrieta constitue en ce sens un matériau de premier ordre pour qui serait soucieux de décrire le travail de qualification inhérent à la fabrique de la théologie et, par là même, de saisir, dans leurs spécificités cultuelles et esthétiques, certaines des controverses qui ont traversé le Mouvement liturgique en amont du Concile Vatican II. 